\title{
El argumento vertebrador del Sentimiento Trágico de la Vida, de Miguel de Unamuno
}

\author{
The central argument of Miguel de Unamuno's \\ The Tragic Sense of Life
}

ALBERTO OYA*

Resumen: En su Sentimiento Trágico de la Vida, Miguel de Unamuno argumenta que necesitamos creer en Dios y que esta necesidad es suficiente para justificar la adopción de la creencia religiosa. El objetivo de este artículo es reconstruir y analizar el argumento de Miguel de Unamuno, el cual constituye, sin lugar a dudas, el eje vertebrador del Sentimiento Trágico de la Vida. En este artículo, defenderé: primero, que el argumento no puede usarse para justificar la adopción de la creencia religiosa; segundo, que el argumento parece ser más convincente si se entiende en términos de deseo y no de necesidad; tercero, que ya sea en términos de deseo o necesidad, lo que realmente demuestra el argumento es el conflicto entre nuestro desear, o necesitar, creer en Dios, por un lado, y nuestra falta de licitud epistémica para adoptar dicha creencia, por otro lado.

Palabras clave: Miguel de Unamuno, creencia religiosa, Del Sentimiento Trágico de la Vida, inmortalidad, fe.

\begin{abstract}
In his The Tragic Sense of Life, Miguel de Unamuno argues that we need to believe in God and that this necessity is enough in order to justify that we adopt the religious belief. The aim of this paper is to reconstruct and analyze Miguel de Unamuno's argument, which is, without any doubt, the guideline of The Tragic Sense of Life. In this paper, I will argue: first, that the argument cannot be used in order to justify our adoption of the religious belief; second, that the argument seems to be more convincing if it is read in terms of desire and not in terms of necessity; third, that in both cases, the desire-reading and the necessity-reading, what the argument really shows is that there is a conflict between our desire to, or our need to, believe, on the one hand, and our lack of epistemic lawfulness for adopting the religious belief, on the other hand.
\end{abstract}

Keywords: Miguel de Unamuno, religious belief, The Tragic Sense of Life, immortality, faith.

\section{Introducción}

En Del Sentimiento Trágico de la Vida (de ahora en adelante: Sentimiento Trágico), Miguel de Unamuno trata de justificar la adopción de la creencia religiosa partiendo de nuestra necesidad de no morir. Es en este sentido que la argumentación ofrecida por Una-

Fecha de recepción: 06/03/2016. Fecha de aceptación: 15/07/2016.

* Graduado en Filosofía (Universitat de Girona: UdG), Graduado en Geografía e Historia (Universidad Nacional de Educación a Distancia: UNED), y Máster en Filosofía Analítica (Universitat de Barcelona: UB). Actualmente cursando estudios de Doctorado en la Universitat de Girona. Publicaciones recientes en Daimon: “Es la medicalización un fenómeno negativo? Un análisis de las consecuencias que suelen atribuirse a la medicalización” (en prensa).Contacto: alberto.oya.marquez@gmail.com 
muno es muy similar a la que podemos encontrar en la apuesta de Pascal ${ }^{1}$ y en "The Will to Believe" de William James²: todos estos autores pretenden justificar la creencia religiosa obviando la cuestión de la existencia de Dios y partiendo de las necesidades y deseos del propio creyente, junto con la consideración de que la creencia religiosa no es una cuestión que pueda ser resuelta a partir de las evidencias disponibles.

En este artículo reconstruiré y analizaré el argumento ofrecido por Miguel de Unamuno. Dicho argumento, aunque no es explícitamente formulado por Unamuno, constituye, sin lugar a dudas, el eje central del Sentimiento Trágico, y así resultará claro a quien haya leído con un mínimo de atención dicha obra.

\section{Primera parte: la creencia en Dios satisface nuestra necesidad de no morirnos nunca}

La primera premisa del argumento es expresada con claridad por Unamuno nada más empezar el Sentimiento Trágico. Dicha premisa puede ser formulada como sigue:

\section{(1) Necesitamos la inmortalidad}

La inmortalidad descrita en (1) debe entenderse como un no morirse nunca, ${ }^{3}$ un mantener la unidad fenoménica, ${ }^{4}$ un no «romper con la unidad y la continuidad de mi vida». ${ }^{5}$ Dicho de otro modo: lo que necesitamos es seguir siendo, después de la muerte, los mismos que somos ahora. En palabras del autor:

No quiero morirme, no, no quiero ni quiero quererlo; quiero vivir siempre, siempre, siempre, y vivir yo este pobre yo que me soy y me siento ser ahora y aquí, y por esto me tortura el problema de la duración de mi alma, de la mía propia. ${ }^{6}$

La necesidad descrita en (1), dice Unamuno, es el «[...] único y verdadero problema vital, [...] [el] que más a las entrañas nos llega [...]». ${ }^{7}$ No se trata, pues, de un simple deseo o de una necesidad cualquiera sino de nuestra mayor necesidad, de «[...] aquello que necesito para vivir». 8

1 Pascal, B. Penseés. Paris: Libraire Générale Française, 1972, pp. 111-117.

2 James, W. "The Will to Believe", 1896; en: James, W. The Will to Believe and other Essays in Popular Philosophy. New York: Longman Green and Co. 1897, pp. 1-31.

3 Unamuno, M. Del Sentimiento Trágico de la Vida, 1913, p. 113; en: Unamuno, M. Obras Completas (vol. VII: Meditaciones y Ensayos Espirituales). Madrid: Escelicer, 1967, pp. 107-302.

4 Ibid.cap. V, p. 160.

5 Ibid.cap. I, p. 115.

6 Ibid. cap. III, p. 136. De ahí lo que dice Unamuno en varias ocasiones sobre el Infierno: «Y he de confesar, en efecto, por dolorosa que la confesión sea, que nunca, en los días de la fe ingenua de mi mocedad, me hicieron temblar las descripciones, por truculentas que fuesen, de las torturas del infierno, y sentí siempre ser la nada mucho más aterradora que él. El que sufre vive, y el que vive sufriendo ama y espera, [...] y es mejor vivir en dolor que no dejar de ser en paz. En el fondo, era que no podía creer en esa atrocidad de un infierno, de una eternidad de pena, ni veía más verdadero infierno que la nada y su perspectiva» (Ibid. cap. III, p. 135; véase también: Ibid. cap. I, p. 114; Ibid. cap. X, p. 254)

7 Ibid.cap. I, p. 111.

8 Ibid. cap. III, p. 137. Véase también: Ibid. conclusión, p. 296 (la cursiva es de Unamuno): “[...] la suprema necesidad humana es la de no morir, la de gozar por siempre la plenitud de la propia limitación individual" 
Sin embargo, parece demasiado exagerado calificar este anhelo de inmortalidad en términos de necesidad. Pues aunque resulta evidente que ninguno de nosotros quiere, al menos en circunstancias normales, dejar de ser, es realmente discutible que necesitemos de la inmortalidad para «[...] poder vivir esta [vida] y soportarla y darle sentido y finalidad».9 Si se está de acuerdo con esto, parece, pues, que lo más adecuado es reescribir (1) en términos de deseo -esto es: (1**) Deseamos la inmortalidad. Por el momento, me centraré en la lectura original del argumento; más adelante veremos qué sucede con el argumento si aceptamos $\left(1^{* *}\right)$ en vez de $(1)$.

Esta necesidad de no morirnos nunca es, de acuerdo con Unamuno, un sentimiento, algo afectivo; contra el cual no caben, por tanto, razones..$^{10}$ Se trata, al fin y al cabo, de un «hecho», ${ }^{11}$ de una necesidad que «[...] se nos plantea como se nos plantea el hambre».12

A pesar de ser un sentimiento, de algo que se tiene o no se tiene, en los primeros capítulos del Sentimiento Trágico, Unamuno se esfuerza por dar algunas consideraciones a favor de juzgar (1) como un sentimiento esencial al hombre..$^{13}$ Así, todo lo que dice Unamuno acerca de que la necesidad de no morir del todo es el punto de partida de toda filosofía y de toda religión, ${ }^{14}$ del hecho de que el hombre sea el único «animal guardamuertos», ${ }^{15}$ del por qué buscamos la gloria y el reconocimiento, ${ }^{16} \mathrm{y}$ de las relaciones sexuales,,${ }^{17}$ debe ser tomado en este sentido.

El último apunte que hace Unamuno relativo a (1) es que la cuestión acerca de nuestra inmortalidad o mortalidad no puede ser resuelta sobre bases racionales. ${ }^{18}$ Lo único que hay acerca de esta cuestión es, pues, incertidumbre -en palabras del autor:

En un escondrijo, el más recóndito del espíritu, sin saberlo acaso el mismo que cree estar convencido de que con la muerte acaba para siempre su conciencia personal, su memoria, en aquel escondrijo le queda una sombra, una vaga sombra de sombra de incertidumbre, y mientras él se dice: "ea, ja vivir esta vida pasajera que no hay otra!”, el silencio de aquel escondrijo le dice: “¡quién sabe!...”. Cree acaso no oírlo, pero lo oye. Y en un repliegue también del alma del creyente que guarde más fe en la vida futura, hay una voz tapada, voz de incertidumbre, que le cuchichea al oído espiritual: “iquién sabe!...”. Son estas voces acaso como el zumbar de un mosquito cuando el vendaval brama entre los árboles del bosque; no nos damos cuenta de ese zumbido y, sin embargo, junto con el fragor de la tormenta nos llega al oírlo. ¿Cómo podríamos vivir, si no, sin esa incertidumbre? ${ }^{19}$

$9 \quad$ Ibid.cap.X, p. 261.

10 Ibid.cap. I, p. 117; Ibid. cap. III, p. 136. Esto no quiere decir, sin embargo, que no podamos hablar de ello, pues de lo contrario sería como «[...] si se le dijera a uno a quien le han tenido que amputar una pierna, que de nada le sirve pensar en ello» (Ibid. cap. I, p. 119).

11 Ibid.cap. VI, p. 185.

12 Ibid.cap. VI, p. 175.

13 Esencial, al menos, a todos los hombres normales; esto es: sin tener en cuenta a «los anormales por barbarie o por supercultura» (Ibid. concl., p. 296).

14 Ibid. cap. II, p. 131; Ibid. cap. III, p. 132.

15 Ibid.cap. III, p. 133.

16 Ibid. cap. III, pp. 139-140.

17 Ibid.cap. VII, p. 188.

18 Ibid.cap. V, p. 171; Ibid.cap. VI, p. 175.

19 Ibid.cap. VI, p. 179. 
La segunda premisa del argumento, también formulada en los primeros capítulos del Sentimiento Trágico, especialmente en el capítulo IV, puede ser reconstruida así:

\section{(2) La creencia en Dios satisface la necesidad descrita en (1)}

Aún cuando todas las religiones afirman la inmortalidad humana de uno u otro modo, ${ }^{20}$ dada la peculiaridad del sentido de inmortalidad usado en (1), no todas las creencias religiosas pueden satisfacer nuestra necesidad de no morir del todo. ${ }^{21}$ Así, por ejemplo, postular que el alma es una sustancia eterna y distinta del cuerpo no satisface en absoluto nuestro anhelo de inmortalidad, pues lo que queremos es unidad fenómenica, seguir siendo, después de la muerte, los que somos aquí y ahora -en palabras del autor:

La inmortalidad del alma pura, sin alguna especie de cuerpo o periespíritu, no es inmortalidad verdadera. Y en el fondo, el anhelo de prolongar esta vida, esta y no otra, esta de carne y de dolor, esta que maldecimos a las veces tan sólo porque se acaba. ${ }^{22}$

Por razones similares, Unamuno concluye que el «Dios-Idea», ${ }^{23}$ el Dios racional de la teología escolástica, es también incapaz de satisfacer (1). ${ }^{24}$ Tampoco la visión beatífica sirve, pues ésta no es más que un «perdernos y anegarnos en Él» ${ }^{25}$ y, por tanto, conlleva una pérdida de nuestra propia unidad fenoménica. ${ }^{26}$ Por motivos parecidos, Unamuno rechaza también el ascetismo religioso. ${ }^{27}$ Por otro lado, niega la capacidad de cualquier forma de panteísmo de satisfacer la necesidad descrita en (1) pues:

Decir que todo es Dios, y que al morir volvemos a Dios, mejor dicho seguimos en Él, nada vale a nuestro anhelo, pues si es así, antes de nacer, en Dios estábamos, y si volvemos al morir adonde antes de nacer estábamos, el alma humana, la conciencia individual, es perecedera. ${ }^{28}$

20 Esto es lo que parece indicar Unamuno cuando dice que: «Un día, hablando con un campesino, le propuse la hipótesis de que hubiese, en efecto, un Dios que rige cielo y tierra, Conciencia del Universo, pero que no por eso sea el alma de cada hombre inmortal en el sentido tradicional y concreto. Y me respondió: "Entonces, ¿para qué Dios?"» (Ibid. cap. I, p. 111).

21 Ibid. cap. III, pp. 136-137: «Y vienen queriendo engañarnos con un engaño de engaños, y nos hablan de que nada se pierde, de que todo se transforma, muda y cambia, que ni se aniquila el menor cachito de materia ni se desvanece del todo el menor golpecito de fuerza, ; $y$ hay quien pretende darnos consuelo con esto! ¡Pobre consuelo! Ni de mi materia ni de mi fuerza me inquieto, pues no son mías mientras no sea yo mismo mío, esto es, eterno. No, no es anegarse en el gran Todo, en la materia o en la Fuerza infinitas y eternas o en Dios lo que anhelo; no es ser poseído por Dios, sino poseerle, hacerme yo Dios sin dejar de ser el que ahora os digo esto. No nos sirven engañifas de monismo; ¡queremos bulto y no sombra de inmortalidad!»

22 Ibid. cap. X, p. 246.

23 Ibid.cap. VIII, p. 204.

24 Ibid. cap. V, p. 163 y ss.

25 Ibid.cap. IX, p. 238.

26 Ibid. cap. X, p. 242.

27 Ibid. cap. XI, p. 277: «¿Y se comprende, por otra parte, que se quiera ganar la otra vida, la eterna, renunciando a ésta, a la temporal? Si algo es la otra vida, ha de ser continuación de ésta, y sólo como continuación, más o menos depurada de ella, la imagina nuestro anhelo, y si así es, cual sea esta vida del tiempo será la de la eternidad».

28 Ibid.cap. V, p. 161. 
Hay, sin embargo, un Dios que sí satisface nuestro anhelo de inmortalidad. El «Dios biótico», ${ }^{29}$ el Dios del Cristianismo primitivo, sí satisface la necesidad descrita en (1). ${ }^{30}$ Es en este sentido que, por ejemplo, Unamuno afirma que la resurrección de Cristo no es otra cosa que «[...] una garantía de nuestra resurrección personal, en alma y también en cuerpo [...]». ${ }^{31}$ Y este «Dios biótico» es el Dios, digámoslo así, popular; en el que de hecho cree la gente. ${ }^{32}$

Hay una objeción posible a (2). Podría decirse que no es la creencia en Dios sino la existencia de Dios lo que propiamente satisface la necesidad descrita en (1). Una posible respuesta a esto es afirmar que la creencia en Dios es un paso previo, una condición necesaria, para la satisfacción de (1). Unamuno parece tener algo así en mente cuando dice:

“QQue lo haga todo Dios!”, dirá alguien; pero es que si el hombre se cruza de brazos, Dios se echa a dormir. ${ }^{33}$

Esta respuesta es discutible, pues uno diría que, si somos o no inmortales, lo somos con independencia de que nosotros creamos o no serlo. En cualquier caso, demos la razón a Unamuno y asumamos, para los propósitos de desarrollo del argumento, que creer en Dios es una condición necesaria para que Éste nos haga inmortales.

\section{Segunda parte: necesitamos de la creencia en Dios}

La tercera premisa del argumento es la siguiente:

\section{(3) Necesitamos satisfacer nuestras necesidades}

Nótese que (3), aún siendo necesaria para el buen funcionamiento del argumento, no aparece de forma explícita en El Sentimiento Trágico. En cualquier caso, (3) parece ser obvia, en tanto que parece derivarse del propio concepto de necesidad, y, por tanto, es probable que Unamuno la diera por sentada.

Una vez habiendo visto (1)-(3), podemos reconstruir el argumento de Unamuno como sigue:

(1) Necesitamos la inmortalidad

(2) La creencia en Dios satisface la necesidad descrita en (1)

(3) Necesitamos satisfacer nuestras necesidades

(4) Necesitamos creer en Dios

29 Ibid. cap. VIII, p. 207.

30 Ibid.cap. IV, p. 155.

31 Ibid.cap. IV, p. 152.

32 Ibid. cap. VIII, p. 214: «Mejor es decir que es Dios verdadero Aquél a quien se reza y se anhela de verdad. [...] El viejo Padre de luengas barbas y melenas blancas, que aparece entre nubes llevando la bola del mundo en la mano, es más vivo y más verdadero que el ens realissimum de la teodicea» (la cursiva es de Unamuno).

33 Ibid.cap. XI, p. 277. 
Es importante hacer notar que (4), por sí solo, no dice nada acerca de nuestra licitud de adoptar una actitud creyente: que necesitemos creer no implica que podamos creer.

Unamuno ofrece un par de apuntes que parecen ser de importancia para su intento de justificar nuestra licitud de adoptar una actitud creyente a partir de (4). En primer lugar, dice Unamuno, no puede probarse ni que Dios existe ni que no existe, tampoco que somos inmortales o que no lo somos; ${ }^{34}$ lo que equivale a decir que no tenemos evidencias suficientes para creer en ninguna de estas posibilidades. En segundo lugar, Unamuno afirma que tenemos «hambre de Dios», 35 que sentimos su falta. Unamuno en ocasiones parece indicar que realmente sentimos a Dios ${ }^{36}$ con lo cual parece indicar que esto podría tomarse como una evidencia epistémica en favor de la creencia de Dios. De ser así, tendríamos una razón para adoptar la creencia religiosa. Sin embargo, la interpretación más natural de esta «hambre de Dios», en caso de que la haya, es, a mi juicio, tomarlo simplemente como una expresión de nuestra necesidad descrita en (1).

Pues bien, dado que necesitamos la creencia en Dios, y dado que no tenemos ninguna evidencia que indique que Dios exista o no exista, ¿por qué no íbamos a adoptar la creencia en Dios?

El problema es que, por mucho que necesitemos la creencia religiosa, no podemos decidir creer que Dios existe, pues creer no es una cuestión de voluntad. La razón de esto fue puesta de manifiesto por Bernard Williams en su ensayo "Deciding to Believe" ${ }^{37}$ Dicho brevemente: es un rasgo constitutivo del creer el que no podamos creer que $\mathrm{P}$ sin creer que nuestra creencia que $\mathrm{P}$ es verdadera; pero si nuestra creencia que $\mathrm{P}$ pudiera responder a un acto volitivo, entonces deberíamos de poder creer que $\mathrm{P}$ sin necesariamente creer que nuestra creencia que $\mathrm{P}$ es verdadera, pues la creencia que P no estaría necesariamente basada en $\mathrm{P}$, sino en nuestra decisión de creer que P.

Unamuno parece ser consciente de esto y responde ofreciendo un nuevo sentido de creer:

El creer es una forma de conocer, siquiera no fuese otra cosa que conocer nuestro anhelo vital y hasta formularlo. Sólo que el término creer tiene en nuestro lenguaje corriente una doble y hasta contradictoria significación, queriendo decir por una parte el mayor grado de adhesión de la mente a un conocimiento como verdadero, de otra parte una débil y vacilante adhesión. Pues si en un sentido creer algo es el mayor asentimiento que cabe dar, la expresión "creo que sea así, aunque no estoy de ello seguro", es corriente y vulgar. ${ }^{38}$

34 Ibid. cap. V, pp. 170-171; Ibid.cap. VI, p. 175; Ibid. cap. VI, p. 179.

35 Ibid.cap. VIII, p. 208.

36 Ibid. cap. VIII, p. 209: «[...] Dios mismo, no ya la idea de Dios, puede llegar a ser una realidad inmediatamente sentida, y aunque no nos expliquemos con su idea ni la existencia ni la esencia del Universo, tenemos a las veces el sentimiento directo de Dios, sobre todo en los momentos de ahogo espiritual. Y este sentimiento -obsérvese bien, porque en esto estriba todo lo trágico de él y el sentimiento trágico de toda vida-, es un sentimiento de hambre de Dios».

37 Williams, B. "Deciding to Believe", 1973; en: Williams, B. Problems of the Self. New York: Cambridge University Press, 1973, pp. 136-151.

38 Unamuno, M. op. cit. cap. IX, p. 220. 
Este nuevo sentido de creencia no es otra cosa que un «tener fe»; y la fe es, dice Unamuno, «[...] fe en la esperanza; creemos lo que esperamos». ${ }^{39}$ Es decir: creer en el sentido de, digámoslo así, tener esperanzas de que la creencia sea verdadera. Y este sentido de creencia, el cual involucra un elemento de incertidumbre, ${ }^{40}$ sí puede ser considerado una cuestión de voluntad. ${ }^{41}$

Dejando de lado la cuestión de si nos es lícito llamar a esto creencia, el problema es que este «tener esperanzas de que la creencia sea verdadera» no es el significado de creencia requerido para el argumento expresado en (1)-(4). Resulta claro que el argumento no puede reconstruirse así:

(1) Necesitamos la inmortalidad

(2*) La creencia en Dios -esto es: tener esperanzas de que la creencia en Dios sea verdadera- satisface la necesidad descrita en (1)

(3) Necesitamos satisfacer nuestras necesidades

(4*) Necesitamos creer en Dios -esto es: necesitamos tener esperanzas de que la creencia en Dios sea verdadera.

Pues $(2 *)$ no es cierto: tener esperanzas de que la creencia en Dios sea verdadera no satisface la necesidad descrita en (1); es sólo el que tomemos como verdadera la existencia de Dios lo que satisface la necesidad descrita en (1).

Una posible respuesta a todo esto es postular que el creer crea el objeto de la creencia. Unamuno, parafraseando a Pascal cuando dice aquello de «[...] empieza por tomar agua bendita y acabarás creyendo», ${ }^{42}$ parece abogar por esta posibilidad. El único argumento ofrecido por Unamuno que parece pretender justificar esta controvertida tesis es el siguiente:

La fe es, pues, si no potencia creativa, flor de la voluntad, y su oficio crear. La fe crea, en cierto modo, su objeto. Y la fe en Dios consiste en crear a Dios y como es Dios el que nos da la fe en Él, es Dios el que se está creando a sí mismo de continuo en nosotros. ${ }^{43}$

Sin embargo, tal y como es aquí formulado, el argumento resulta ininteligible: ¿cómo puede Dios darnos la fe que no tenemos si el hecho que no la tengamos implica que Dios no ha sido aún creado? Quizás lo que realmente quiere decir aquí Unamuno sea algo similar a lo que ya dijo William James en su "The Will to Believe"; esto es: que hay casos en los que mantener la falsa creencia que $\mathrm{P}$ nos llevará a actuar cómo A (siendo A la manera más adecuada de actuar), y A hará que la anterior falsa creencia que $\mathrm{P}$ se vuelva verdadera. ${ }^{44}$

39 Ibid.cap. IX, p. 227.

40 Ibid. cap. IX, p. 222.

41 Ibid. cap. IX, pp. 222-223.

42 Ibid.cap. XI, p. 263.

43 Ibid.cap. IX, p. 223.

44 James, W. op. cit. cap. IX, pp. 22-25. Uno de los ejemplos propuestos por James es el siguiente: «Un tren lleno de pasajeros (suficientemente valientes tomados individualmente) será asaltado por unos pocos bandoleros 
Aun cuando se identifique creer con «tener esperanzas de que la creencia sea verdadera», ${ }^{45}$ el problema de esto es que, si bien en casos como los que usa James, vinculados a relaciones personales o sociales, que sucede tal cosa podría ser algo a primera vista fácil de aceptar -pues con nuestras creencias variamos nuestro actuar, y éste tiene consecuencias no sólo individuales sino también sociales, que pueden hacer variar el contexto en qué nos encontramos-, no sucede lo mismo en el caso de la creencia en Dios, pues, aún sin entrar en disquisiciones teológicas, resulta cuanto menos extraño decir que Dios es creado por el hombre.

\section{Deseo, que no necesidad}

Al principio de este artículo dije que calificar el anhelo de inmortalidad en términos de necesidad parece ser algo excesivo, pues, aun cuando parece innegable que ninguno de nosotros quiere, al menos en circunstancias normales, dejar de ser, también parece claro que muchos de nosotros dudaríamos en aceptar que no podemos concebir «[...] la libertad de un corazón ni la tranquilidad de una conciencia que no estén seguras de su perdurabilidad después de la muerte». ${ }^{46} \mathrm{Si}$ se está de acuerdo conmigo, lo más adecuado parece ser, pues, entender este anhelo de inmortalidad en términos de deseo y no de necesidad -esto es: reescribir (1) como (1**) Deseamos la inmortalidad.

Si optamos por $\left(1^{* *}\right)$, y dado que no necesitamos satisfacer todos nuestros deseos, el argumento de Unamuno debería de reescribirse como sigue:

$(1 * *)$ Deseamos la inmortalidad

$(2 * *)$ La creencia en Dios satisface el deseo descrito en (1)

(3**) Deseamos satisfacer nuestros deseos

(4**) Deseamos creer en Dios

En cualquier caso, nótese que, independientemente de si se toma el término creencia en el sentido ordinario de la palabra o si se entiende como un tener fe, $(4 * *)$ sigue teniendo los mismos problemas que (4) si se pretende usar para justificar la adopción de la creencia religiosa.

simplemente porque estos últimos pueden contar los unos con los otros, mientras que cada uno de los pasajeros teme que si hace un movimiento de resistencia recibirá un disparo antes de que algún otro pasajero lo defienda. Si creyéramos que todos los pasajeros del tren se alzarían al momento con nosotros, cada uno de nosotros se alzaría, y el robo ni tan siquiera se intentaría llevar a cabo. Hay casos, por tanto, en los que no puede aparecer un hecho excepto que exista una fe previa en su aparición» (James, W. op. cit. cap. IX, pp. 24-25. La traducción al castellano es mía).

45 Si se toma creer en el sentido ordinario de la palabra, entonces lo que dice James, y muy probablemente Unamuno tenga también en mente, no afecta a nuestros procesos de formación de creencias. En caso contrario deberíamos de aceptar que podemos formarnos una creencia en vistas únicamente de su adecuación, sin importarnos si la creencia es verdadera o falsa. Pero no podemos formarnos una creencia en vistas únicamente de su adecuación: si éste fuera el caso, entonces debería ser posible que nos formáramos la creencia que P sin formarnos la creencia que nuestra creencia que $\mathrm{P}$ es verdadera. Sin embargo, no podemos hacer tal cosa. Así pues, aunque fuera necesario que creyéramos para que la creencia fuera verdadera, ello no podría hacernos creer.

46 Unamuno, M. op. cit. cap. IV, p. 150. 
Sin embargo, el punto interesante es que, aun cuando se acepte $\left(1^{* *}\right)$ y no (1), el problema de fondo sigue sin resolverse; esto es: sigue sin resolverse lo que Unamuno gusta de llamar «el sentimiento trágico de la vida», el conflicto entre nuestro desear creer en Dios, por un lado, y nuestra falta de licitud epistémica para adoptar dicha creencia, por otro lado. Usando las palabras de Unamuno, la conclusión es, pues, que, una vez aceptadas las premisas del argumento, «[n]i el sentimiento logra hacer del consuelo verdad, ni la razón logra hacer de la verdad consuelo $[\ldots] \gg .{ }^{47}$

\section{Conclusión}

A lo largo de este artículo, he tratado de reconstruir y analizar el argumento ofrecido por Miguel de Unamuno en su Sentimiento Trágico, el cual constituye el eje vertebrador de dicha obra. Las principales conclusiones a las que podemos llegar son las siguientes.

En primer lugar, he indicado que el argumento de Unamuno no puede usarse para justificar la adopción de la creencia religiosa, pues creer no tiene nada que ver con la voluntad. He señalado también que Unamuno parece ser consciente de esto, y que, como respuesta, ofrece un nuevo sentido de creer, identificando el creer con el tener fe, que sí está relacionado con la voluntad. Pero entonces el argumento tampoco permite justificar la adopción de la creencia religiosa, pues el sentido de creer usado en él no es el de tener fe. Tampoco el argumento de Unamuno para probar que el creer crea el objeto de la creencia parece ser convincente.

Por otro lado, he indicado que el argumento parece ser más convincente si se entiende en términos de deseo y no de necesidad; pero que, aún así, el argumento no puede usarse para justificar la adopción de la creencia religiosa.

Por último, he señalado que lo que realmente parece probar el argumento es el conflicto entre nuestro desear creer en Dios, por un lado, y nuestra falta de licitud epistémica para adoptar dicha creencia, por otro lado. La falta de una solución clara a este conflicto es lo que hace que el sentimiento sea trágico.

\section{Referencias}

James, W. "The Will to Believe", 1896; en: James, W. The Will to Believe and other Essays in Popular Philosophy. New York: Longman Green and Co. 1897.

Pascal, B. Penseés. Paris: Libraire Générale Française, 1972.

Unamuno, M. Del Sentimiento Trágico de la Vida, [1913]. En Unamuno, M. Obras Completas (vol. VII: Meditaciones y Ensayos Espirituales). Madrid: Escelicer, 1967, pp. 107-302.

Williams, B. "Deciding to Believe". En: Williams, B. Problems of the Self. New York: Cambridge University Press, 1973.

47 Ibid.cap. V, p. 171. 